\title{
ASESORÍA GENÉTICA EN CÁNCER
}

\section{CANCER GENETIC COUNSELING.}

María del Carmen Castro-Mujica ${ }^{1,3}$, Claudia Barletta-Carrillo,2, Juan Carlos Gómez de la Torre-Pretell.

\section{Sr. Editor}

El cáncer es una enfermedad caracterizada por la transformación maligna y crecimiento descontrolado de las células debido a múltiples alteraciones en su genoma ${ }^{(1)}$. Es considerado un problema de salud pública porque afecta a millones de personas en el mundo y ocasiona la muerte, principalmente, por la falta de detección precoz.

El cáncer se puede clasificar en ${ }^{(2)}:$ 1) Esporádico ( 70\%): generalmente en personas mayores de 50 años y debido a mutaciones espontáneas en el genoma de las células de un órgano, desencadenadas por factores ambientales, exposición a carcinógenos, envejecimiento, etc; 2) Familiar ( 20-25\%): debido a mutaciones en genes de baja penetrancia, donde no se observa un patrón de herencia; y 3) Hereditario ( 5-10\%): debido a mutaciones germinales en genes que se transmiten bajo un patrón de herencia, pueden heredarse a los descendientes y confieren un mayor riesgo a desarrollar cáncer a edad más temprana comparado con los casos esporádicos.

Hasta la fecha se han descrito aproximadamente 200 Síndromes hereditarios de predisposición al cáncer (2), entre los cuáles se encuentran el Síndrome cáncer de mama/ovario hereditario, Síndrome de Lynch, Síndrome de cáncer gástrico difuso hereditario, entre otros. Cuando existe la sospecha de estos casos, es necesario realizar una evaluación y asesoría genética, así como la posterior solicitud de estudios genéticos según determinadas indicaciones ${ }^{(3)}$ (Tabla 1 ).

Tabla 1: Indicaciones para referir pacientes con sospecha de cáncer hereditario

\begin{tabular}{ll} 
1. & Dos o más personas con cáncer en una familia. \\
\hline 2. & Varios miembros de una familia afectados por el mismo tipo de cáncer. \\
\hline 3. & Aparición del cáncer a edad temprana (antes de los 50 años). \\
\hline 4. & Bilateralidad en el caso de afectación de órganos pares y/o multifocalidad. \\
\hline 5. & Más de un cáncer primario en la misma persona. \\
\hline 6. & Asociación del cáncer con defectos del desarrollo.
\end{tabular}

La asesoría genética en cáncer permite: 1) evaluar al paciente y conocer sus antecedentes oncológicos personales y familiares mediante la elaboración del árbol genealógico; 2) establecer el diagnóstico de cáncer hereditario según criterios clínicos-genéticos para cada síndrome; 3) solicitar estudios genéticos e informar los posibles resultados; y 4) explicar completa y objetivamente los resultados, las causas genéticas por las cuáles se desarrolló el cáncer, así como sus implicancias. Además, debido al impacto emocional en el paciente tras conocer los resultados, es importante referirlo a una evaluación psico-oncológica.

El principal objetivo de un estudio genético, en estos casos, es identificar la alteración responsable del cáncer. La Sociedad Americana de Oncología Clínica ${ }^{(4)}$ recomienda que se soliciten estudios genéticos cuando exista una historia personal o familiar sugestiva de cáncer hereditario y cuando los resultados puedan ser de ayuda en el diagnóstico o influyan en el manejo médico. Además, existen criterios para escoger a la persona idónea a realizarse este estudio ${ }^{(5)}$ : 1) elegir a la persona con cáncer por sobre el resto de miembros en una familia; y 2) si existen varias personas afectadas, elegir al que presentó el cáncer a edad más temprana o que posea más de un cáncer.

Los resultados del estudio genético pueden ser: 1) Negativos: cuando no se detectan alteraciones genéticas o se identifican variantes benignas o probablemente benignas. 2) Variantes de significado incierto: cuando

1. Facultad Medicina Humana - Universidad Ricardo Palma. Lima, Perú.

2. Laboratorio Biología Molecular - Laboratorio Clínico Roe. Lima, Perú

3 Email de contacto: mc.castro.mujica@gmail.com 
se identifican variantes que hasta la fecha no se ha determinado una asociación con el riesgo incrementado a desarrollar cáncer, pero que su clasificación puede variar en el tiempo; y 3) Positivos: cuando se identifican variantes patogénicas o probablemente patogénicas, permitiendo establecer los riesgos del paciente, el manejo multidisciplinario y la posibilidad de buscar la variante en sus familiares.

En conclusión, la asesoría genética en cáncer permite reducir la morbimortalidad en pacientes con cáncer hereditario y sus familiares mediante un manejo multidisciplinario que establezca medidas preventivas, detección precoz y control de riesgos.

\section{Bibliografía}

1- Yates LR, Campbell PJ. Evolution of the cancer genome. Nat Rev Genet. noviembre de 2012;13(11):795-806.

2. Bandres F, Urioste M. Planteamientos básicos del cáncer hereditario: principales síndromes. Madrid: Fundación Tejerina; 2011, Instituto Roche.

3. Sifri R, Gangadharappa S, Acheson LS. Identifying and testing for hereditary susceptibility to common cancers. CA Cancer J Clin. diciembre de 2004;54(6):309-26.

4. American Society of Clinical Oncology. American Society of Clinical Oncology policy statement update: genetic testing for cancer susceptibility. J Clin Oncol Off J Am Soc Clin Oncol. 15 de junio de 2003;21(12):2397-406.

5. Hampel H, Sweet $K$, Westman JA, Offit K, Eng C. Referral for cancer genetics consultation: a review and compilation of risk assessment criteria. J Med Genet. febrero de 2004;41(2):81-91. 